\title{
Microbial D-xylonate production
}

\author{
Mervi H. Toivari • Yvonne Nygård • Merja Penttilä • \\ Laura Ruohonen • Marilyn G. Wiebe
}

Received: 9 March 2012 / Revised: 5 July 2012 / Accepted: 7 July 2012 / Published online: 9 August 2012

(C) The Author(s) 2012. This article is published with open access at Springerlink.com

\begin{abstract}
D-Xylonic acid is a versatile platform chemical with reported applications as complexing agent or chelator, in dispersal of concrete, and as a precursor for compounds such as co-polyamides, polyesters, hydrogels and 1,2,4butanetriol. With increasing glucose prices, D-xylonic acid may provide a cheap, non-food derived alternative for gluconic acid, which is widely used (about $80 \mathrm{kton} / \mathrm{year}$ ) in pharmaceuticals, food products, solvents, adhesives, dyes, paints and polishes. Large-scale production has not been developed, reflecting the current limited market for D-xylonate. D-Xylonic acid occurs naturally, being formed in the first step of oxidative metabolism of D-xylose by some archaea and bacteria via the action of D-xylose or D-glucose dehydrogenases. High extracellular concentrations of D-xylonate have been reported for various bacteria, in particular Gluconobacter oxydans and Pseudomonas putida. High yields of D-xylonate from D-xylose make $G$. oxydans an attractive choice for biotechnical production. G. oxydans is able to produce D-xylonate directly from plant biomass hydrolysates, but rates and yields are reduced because of sensitivity to hydrolysate inhibitors. Recently, D-xylonate has been produced by the genetically modified bacterium Escherichia coli and yeast Saccharomyces cerevisiae and Kluyveromyces lactis. Expression of $\mathrm{NAD}^{+}$-dependent Dxylose dehydrogenase of Caulobacter crescentus in either E. coli or in a robust, hydrolysate-tolerant, industrial Saccharomyces cerevisiae strain has resulted in D-xylonate titres, which are comparable to those seen with G. oxydans, at a volumetric rate approximately $30 \%$ of that observed with $G$. oxydans. With further development, genetically
\end{abstract}

M. H. Toivari $(\bowtie) \cdot$ Y. Nygård $\cdot$ M. Penttilä $\cdot$ L. Ruohonen •

M. G. Wiebe

VTT, Technical Research Centre of Finland,

P.O. Box 1000, 02044 VTT Espoo, Finland

e-mail: mervi.toivari@vtt.fi modified microbes may soon provide an alternative for production of D-xylonate at industrial scale.

Keywords D-Xylonate $\cdot \mathrm{D}$-Xylose $\cdot$ Oxidation $\cdot \mathrm{D}$-Xylose dehydrogenase $\cdot$ Lignocellulosic hydrolyzate

\section{Introduction}

Sugar acids are currently generating considerable interest because of their potential as platform chemicals and particularly their use as precursors in the manufacture of biomass derived plastics. D-Xylonic acid (Fig. 1), derived from the hemicellulose sugar D-xylose, has applications similar to D-gluconic acid and could serve as a D-gluconic acid substitute, but would be produced from non-food carbohydrate. D-Xylonic acid has been used in dispersal of concrete (Chun et al. 2006), in the production of copolyamides (Zamora et al. 2000) and as a precursor for 1,2,4-butanetriol synthesis (Niu et al. 2003). Several other applications for D-xylonic acid have been patented.

Microbial production of D-xylonate was recognised already at the end of the nineteent century (Bertrand 1898, cited in Lockwood and Nelson 1946) and many species of Pseudomonas, Acetobacter, Aerobacter, Gluconobacter, Erwinia and related genera have been shown to produce D-xylonate (reviewed in Buchert 1990). Periplasmic D-xylose and D-glucose dehydrogenases use the pyrroloquinoline quinol (PQQ) prosthetic group to transfer electrons to cytochrome $\mathrm{c}$ in the respiratory chain, with a corresponding accumulation of D-xylonolactone or D-xylonate in the medium (Galar and Boiardi 1995; Hardy et al. 1993). D-Xylonolactone is the immediate product of the dehydrogenases, but the lactone generally opens spontaneously or with the aid of lactonase produced by the same species (Buchert and Viikari 1988). Some bacteria and also archaea metabolise D-xylonic acid 
Fig. 1 Formation of D-xylonate from $\mathrm{D}$-xylose by $\mathrm{NAD}(\mathrm{P})^{+}$or PQQ-dependent xylose dehydrogenases or glucose oxidase

\section{D-xylose dehydrogenase}<smiles>O[C@H]1CO[C@@H](O)[C@@H](O)[C@H]1O</smiles>

D-xylose

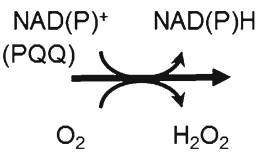

glucose oxidase<smiles>O=C1O[C@H](CO)[C@@H](O)[C@H]1O</smiles>

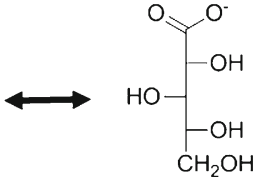

D-xylono-y-lactone

D-xylonate further via non-phosphorylative D-xylose metabolic pathways (Weimberg 1961; Dahms 1974). Cytoplasmic NAD(P) ${ }^{+}$-dependent D-xylose dehydrogenases oxidise D-xylose to D-xylonolactone (Johnsen and Schönheit 2004; Johnsen et al. 2009; Stephens et al. 2007), which is cleaved by lactonase to Dxylonate in the cytoplasm. D-Xylonate may be dehydrated to produce 2-keto-3-deoxy pentanoate, which is further dehydrated and reduced to $\alpha$-ketoglutarate or cleaved by an aldolase to pyruvate and glycolaldehyde. There are also some reports of yeast and other fungi producing D-xylonic acid (Suzuki and Onishi 1973; Kiesling et al. 1962; Kanauchi and Bamforth 2003), although only one gene coding for D-xylose dehydrogenase has been identified in fungal species (Berghäll et al. 2007). Production of D-xylonate from D-xylose by D-glucose oxidase has also been described (Pezzotti and Therisod 2006; Chun et al. 2006) and Aspergillus niger produces D-xylonate when cultivated in suitable conditions (Fig. 2).

Recently, various yeast strains as well as the bacterium Escherichia coli have been engineered to produce D-xylonate, by the introduction of genes encoding D-xylose dehydrogenase (Toivari et al. 2010; Nygård et al. 2011; Liu et al.

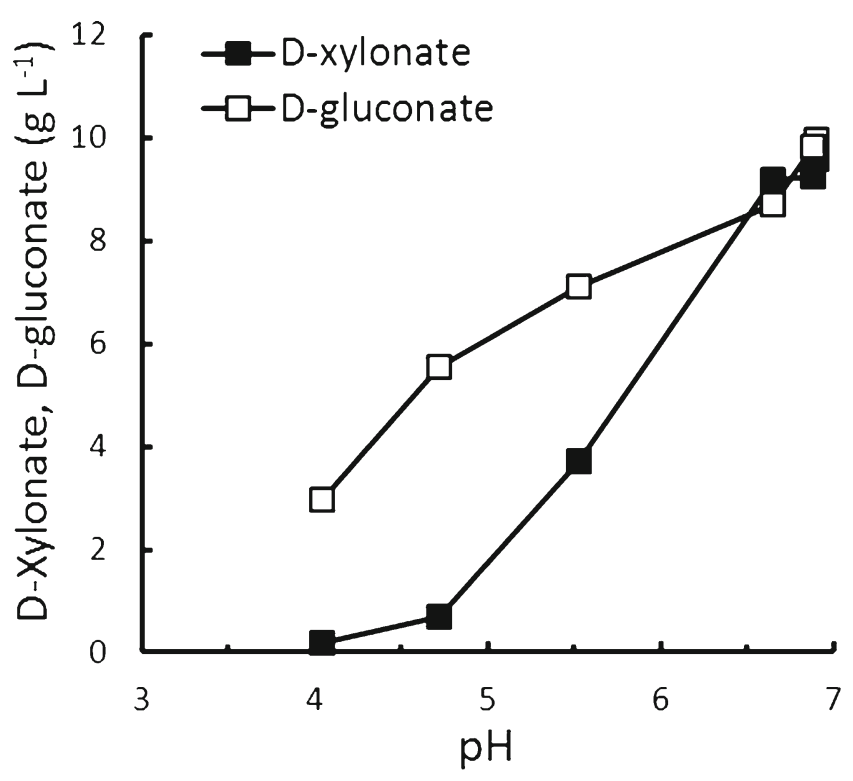

Fig. 2 Production of D-xylonate and D-gluconate by Aspergillus niger ATCC1015 after $79 \mathrm{~h}$ in defined medium with $45 \mathrm{~g}$ D-xylose $1^{-1}$ and $10 \mathrm{~g}$ D-glucose $1^{-1}$ as carbon source. Medium was buffered with 0.1 to $2.0 \%(w / v) \mathrm{CaCO}_{3}$, and average $\mathrm{pH}$ over $79 \mathrm{~h}$ is shown
2011). Gene sequences for several putative D-xylonolactonases have recently been identified (Johnsen et al. 2009; Stephens et al. 2007; Brouns et al. 2006), but the enzymes have not been studied. The mechanism of transport of either the linear or the lactone form of D-xylonate from strains with intracellular D-xylonate production is unknown.

In addition to the microbial production described in this review, D-xylonate can be produced via enzymatic (Pezzotti and Therisod 2006), electrochemical (Jokic et al. 1991) or chemical oxidation (Isbell and Hudson 1932). D-Xylonic acid can also be found in acid sulphite pulping liquor of hardwood (Samuelson and Simonson 1962; Pfister and Sjöström 1977). However, an efficient separation method to obtain D-xylonate from pulping liquor has not been established.

Although a variety of applications for D-xylonic acid have been patented, one of which includes a method for production of crude D-xylonic acid from plant biomass hydrolysate (Chun et al. 2003), bulk production of D-xylonic acid is limited. This review describes the current state in microbial production of D-xylonate with bacteria and fungi.

\section{Bacterial D-xylonate production}

Yields and conversion rates

Of the numerous bacteria described as producers of D-xylonate, species of Pseudomonas (Lockwood and Nelson 1946; Buchert et al. 1986), Gluconobacter (Buchert 1990), Micrococcus (Ohsugi et al. 1970) and Enterobacter (Ishizaki et al. 1973) have been the most productive (Table 1). High yields of D-xylonate are generally associated with poor or no conversion of D-xylose to biomass.

Although the $\mathrm{pH}$ optimum of the Gluconobacter oxydans D-xylose dehydrogenase is 6 , D-xylonate has been produced at $\mathrm{pH} 4.5$ (Buchert 1990) and even at pH 3.5 (Fig. 3, Table 1). Production rates are approximately $2 \mathrm{~g}$ D-xylonate $\mathrm{l}^{-1} \mathrm{~h}^{-1}$ at $\mathrm{pH} 4.5-6.5$, even when biomass concentration is low $\left(0.2 \mathrm{~g}\right.$ biomass $\left.\mathrm{1}^{-1}\right)$ and no cell growth occurs (Table 1, Buchert 1990). We have observed specific production rates up to $12 \mathrm{~g}$ D-xylonate (g biomass) ${ }^{-1} \mathrm{~h}^{-1}$ at $\mathrm{pH}$ 5.6.

Since G. oxydans requires complex growth medium and efficiently converts most sugars to acids rather than biomass, other species may be more cost effective for D-xylonate 
Table 1 D-Xylonate production with G. oxydans, Pseudomonas species, and Enterobacter cloacea, A. niger, and engineered strains of Escherichia coli, S. cerevisiae and K. lactis

\begin{tabular}{|c|c|c|c|c|c|c|c|c|c|}
\hline Species & $\begin{array}{l}\text { D-Xylose } \\
\left(\mathrm{g} \mathrm{l}^{-1}\right)\end{array}$ & $\begin{array}{l}\text { D-Xylonate } \\
\left(\mathrm{g} \mathrm{l}^{-1}\right)\end{array}$ & $\begin{array}{l}\text { Yield }_{\mathrm{P} / \mathrm{S}} \\
\left(\mathrm{g} \mathrm{g}^{-1}\right)\end{array}$ & $\begin{array}{l}\text { Volumetric } \\
\text { productivity } \\
\left(\mathrm{g} \mathrm{l}^{-1} \mathrm{~h}^{-1}\right)\end{array}$ & $\begin{array}{l}\text { Specific productivity } \\
\left.[\mathrm{g} \text { (g biomass })^{-1} \mathrm{~h}^{-1}\right]\end{array}$ & $\mathrm{pH}$ & $\begin{array}{l}\text { Biomass } \\
\left(\mathrm{g} \mathrm{l}^{-1}\right)\end{array}$ & Process & References \\
\hline $\begin{array}{l}\text { G. oxydans } \\
\text { (ATCC621) }\end{array}$ & 100 & 109 & 1.1 & 2.5 & $\sim 1.5$ & 5.5 & 1.7 & Batch & Buchert (1990) \\
\hline $\begin{array}{l}\text { G. oxydans } \\
\text { (ATCC621) }\end{array}$ & 100 & 107 & 1.1 & 2.2 & $\sim 1.5$ & 4.5 & 1.3 & Batch & Buchert (1990) \\
\hline $\begin{array}{l}\text { G. oxydans } \\
\text { (ATCC621) }\end{array}$ & 46 & 51 & 1.1 & 1.8 & 6 & 5.5 & 0.2 & Batch & VTT \\
\hline $\begin{array}{l}\text { G. oxydans } \\
\text { (ATCC621) }\end{array}$ & 40 & 41 & 1.0 & 1.0 & 4 & 3.5 & 0.2 & Batch & VTT \\
\hline $\begin{array}{l}\text { G. oxydans } \\
\text { (ATCC621) }\end{array}$ & 40 & 37 & 1.0 & 1.5 & 2.8 & 5.5 & 0.5 & $\begin{array}{l}\text { Continuous } \\
D=0.04 \mathrm{~h}^{-1}\end{array}$ & VTT \\
\hline P. fragi ATCC4973 & 150 & 162 & 1.1 & 1.4 & 0.2 & 6.5 & 6.9 & Batch & $\begin{array}{l}\text { Buchert and } \\
\text { Viikari (1988) }\end{array}$ \\
\hline P. putida & $\sim 0.4$ & $\sim 0.4$ & $\sim 1$ & $\sim 1.9$ & $\sim 0.7$ & 6.8 & 2.9 & $\begin{array}{l}\text { Continuous } \\
D=0.2 \mathrm{~h}^{-1}\end{array}$ & Hardy et al. (1993) \\
\hline E. cloacea & 200 & 190 & $\sim 1$ & 1.6 & & 6.5 & nd & Batch & Ishizaki et al. (1973) \\
\hline E. coli & 40 & 39 & 1.0 & 1.1 & 0.14 & 7.0 & $\sim 8$ & Batch & Liu et al. (2011) \\
\hline S. cerevisiae Xydl & 20 & 4 & 0.4 & 0.03 & 0.007 & 5.5 & 4.6 & Batch & Toivari et al. (2010) \\
\hline $\begin{array}{l}\text { S. cerevisiae } \\
\text { SUS2DD }\end{array}$ & 23 & 3 & 0.4 & 0.02 & 0.006 & 5.5 & 5.3 & Batch & Toivari et al. (2012) \\
\hline S. cerevisiae $x y l B$ & 23 & 17 & 0.8 & 0.23 & 0.06 & 5.5 & 5 & Batch & Toivari et al. (2012) \\
\hline $\begin{array}{l}\text { S. cerevisiae } \\
\text { B67002 xylB }\end{array}$ & 49 & 43 & 0.8 & 0.44 & 0.06 & 5.5 & 7 & Batch & Toivari et al. (2012) \\
\hline K. lactis Xyd1 & 40 & 19 & 0.6 & 0.16 & 0.03 & 5.5 & 6 & Batch & Nygård et al. (2011) \\
\hline $\begin{array}{l}\text { K. lactis Xyd1 } \\
\triangle X Y L 1\end{array}$ & 23 & 8 & 0.4 & 0.13 & 0.01 & 5.5 & 9 & Batch & Nygård et al. (2011) \\
\hline A. niger ATCC 1015 & 45 & 10 & 0.8 & 0.12 & & $>5.5$ & nd & Batch & VTT \\
\hline
\end{tabular}

For production potential of other bacteria, see (Buchert 1990).

$n d=$ no data, VTT unpublished data from VTT, M.G. Wiebe personal communication

production. Pseudomonas fragi ATCC4973 produces D-xylonate at similar volumetric rates to $G$. oxydans, but at lower specific rate (Table 1, Buchert and Viikari 1988), and production is more sensitive to $\mathrm{pH}$ and hydrolysate inhibitors (Buchert et al. 1986, 1988). Various other bacteria also produce D-xylonate and some such as Gluconoacetobacter diazotrophicus, which has been considered as an alternative to Gluconobacter for D-gluconate production because of its minimal nutritional requirements and low $\mathrm{pH}$ tolerance (Attwood et al. 1991) could also be considered for D-xylonate production.

The first example of bacteria engineered for D-xylonate production was recently described by Liu et al. (2011). By introducing a D-xylose dehydrogenase encoding gene, $x y l B$ from Caulobacter crescentus, into $E$. coli strain W3110 and by blocking the endogenous pathways for Dxylose and D-xylonate metabolism, they were able to produce $39 \mathrm{gl}^{-1}$ D-xylonic acid from $40 \mathrm{gl}^{-1}$ D-xylose in a batch process (Table 1).

Although continuous production of D-xylonate has not been reported, continuous production of D-gluconic (e.g. Attwood et al. 1991), 2-keto-L-gulonic (e.g. Takagi et al.

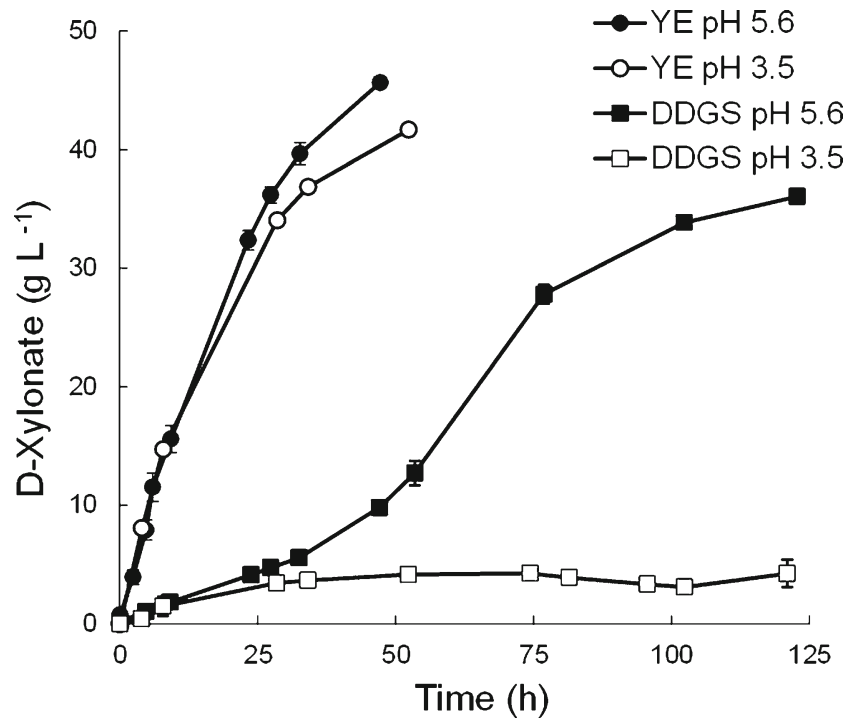

Fig. 3 D-Xylonate production by Gluconobacter oxydans ATCC621 from D-xylose in YE supplemented defined medium with $45 \mathrm{~g} \mathrm{D}$ xylose $1^{-1}$ at $\mathrm{pH} 5.6$ (filled circle) or $\mathrm{pH} 3.5$ (empty circle) and from acid hydrolysed DDGS at pH 5.6 (filled square) or $\mathrm{pH} 3.5$ (empty square). Error bars represent \pm SEM for duplicate cultures 
2009) and 2,5-diketogluconic (e.g. Buse et al. 1992a, b) acids have been described. Hardy et al. (1993) described the production of D-xylonate at a rate of $\sim 4 \mathrm{mmol}$ (g biomass) ${ }^{-1} \mathrm{~h}^{-1}$ as a by-product for enhanced biomass yield of Pseudomonas putida on D-glucose or lactate at $D=0.2 \mathrm{~h}^{-1}, \mathrm{pH} 6.8$ (Table 1). With $G$. oxydans, we have observed continuous production of D-xylonate with $G$. oxydans at a rate of $1.5 \mathrm{~g}$ D-xylonate $^{-1} \mathrm{~h}^{-1}$ at $D=0.04 \mathrm{~h}^{-1}$ with $40 \mathrm{~g} \mathrm{D}$-xylose $\mathrm{l}^{-1}$ and $20 \mathrm{~g} \mathrm{D}$-glucose $\mathrm{l}^{-1}$ at pH 5.5 (Fig. 4, Table 1). In addition, D-gluconate, acetate and biomass were produced. Continuous production at $\mathrm{pH} 4.5$ was also possible (Fig. 4). Conditions for D-xylonate production in fed-batch cultures have not been reported.

\section{Hydrolysate}

Lignocellulosic waste biomass would provide an economic raw material for D-xylonate production, and several studies have been carried out on the conversion of D-xylose to D-xylonate in hemicellulose hydrolysates (Chun et al. 2006; Buchert et al. 1988). These are summarised in Table 2. G. oxydans was found to be more tolerant to toxins in biomass hydrolysate than $P$. fragi, but growth and D-xylonate production were still inhibited by high concentrations of lignocellulosic hydrolysate. Pretreatment by diethylether extraction, adsorption on mixed bed resin or ion exclusion chromatography enabled conversion of D-xylose in hydrolysate to D-xylonate by G. oxydans, with the biggest improvements seen when treated by ion exclusion chromatography (Table 2).

Turkia et al. (2010) also observed a low rate for the conversion of D-xylose to D-xylonate by $G$. oxydans ATCC621 (E97003) in a pentose-rich hydrolysate derived from wheat straw, with incomplete conversion of the Dxylose and a low yield of $\sim 0.7 \mathrm{~g}$ D-xylonate (g D-xylose consumed) ${ }^{-1}$. Overliming (Mohagheghi et al. 2006) the hydrolysate to remove some of the aromatic and aliphatic compounds was sufficient to enable full conversion of the hydrolysate [yield $1.0 \mathrm{~g}$ D-xylonate (g D-xylose consumed $)^{-1}$ ] and to improve the production rate to $1.1 \mathrm{~g} \mathrm{D}-$ xylonate $1^{-1} \mathrm{~h}^{-1}$ with an inoculum of only $1.0-1.5 \mathrm{~g}$ biomass $1^{-1}$ (Fig. 5). The rate was thus only slightly lower than that observed with pure D-xylose and similar to that obtained by hydrolysate treated with ion exclusion chromatography. In contrast, overliming acid hydrolysed dried distillers grain solids (DDGS) from Abengoa Bioenergia Nuevas Tecnologias (ABNT, Spain) resulted in poorer conversion of the Dxylose to D-xylonate than in the untreated hydrolysate (Table 2).

Chun et al. (2006) found that G. oxydans was able to completely convert D-xylose in diluted spent sulphite liquor even though no cell growth occurred. Conversion rates with high cell density $\left(\sim 4.6 \mathrm{~g}\right.$ biomass $\left.1^{-1}\right)$ were comparable to those in ether-extracted birchwood hydrolysate and untreated wheat straw hydrolysate (Table 2, Chun et al. 2006).

In continuous flow culture at $D=0.03 \mathrm{~h}^{-1}$, D-xylonate was produced by $G$. oxydans at a rate of $0.32 \mathrm{~g}$ D-xylonate $\mathrm{l}^{-1} \mathrm{~h}^{-1}$ for up to 3 days (Table 1 ). However, only $\sim 50 \%$ of the D-xylose in the hydrolysate was converted to D-xylonate, and the cells were being washed out. Approximately $76 \%$ D-glucose in the hydrolysate was converted to D-gluconate.

\section{Recombinant yeast for D-xylonate production}

S. cerevisiae and the choice of D-xylose dehydrogenase

Toivari et al. (2010) described the production of D-xylonate by $S$. cerevisiae expressing an $\mathrm{NADP}^{+}$-dependent xylose dehydrogenase from $T$. reesei. The engineered $S$. cerevisiae strains produced up to $3.8 \mathrm{~g}$ D-xylonate $\mathrm{l}^{-1}$ (Table 1). Xylitol $\left(4.8 \mathrm{gl}^{-1}\right)$ was the primary by-product and could be significantly reduced by deleting the aldose reductase encoded by GRE3 (Toivari et al. 2010). Although this demonstrated the
Fig. 4 D-Gluconate, D-xylonate, acetate and biomass production, volumetric D-xylonate production rate and specific D-xylonate production rate by Gluconobacter oxydans ATCC621 in chemostat culture with YE supplemented defined medium containing $10 \mathrm{~g}$ D-glucose $1^{-1}$ and $40 \mathrm{~g}$ D-xylose $1^{-1}$ at $D=0.04 \mathrm{~h}^{-1}, \mathrm{pH} 5.5$ or 4.5. Error bars represent \pm SEM for triplicate $(\mathrm{pH} 5.5)$ or duplicate ( $\mathrm{pH} 4.5)$ samples
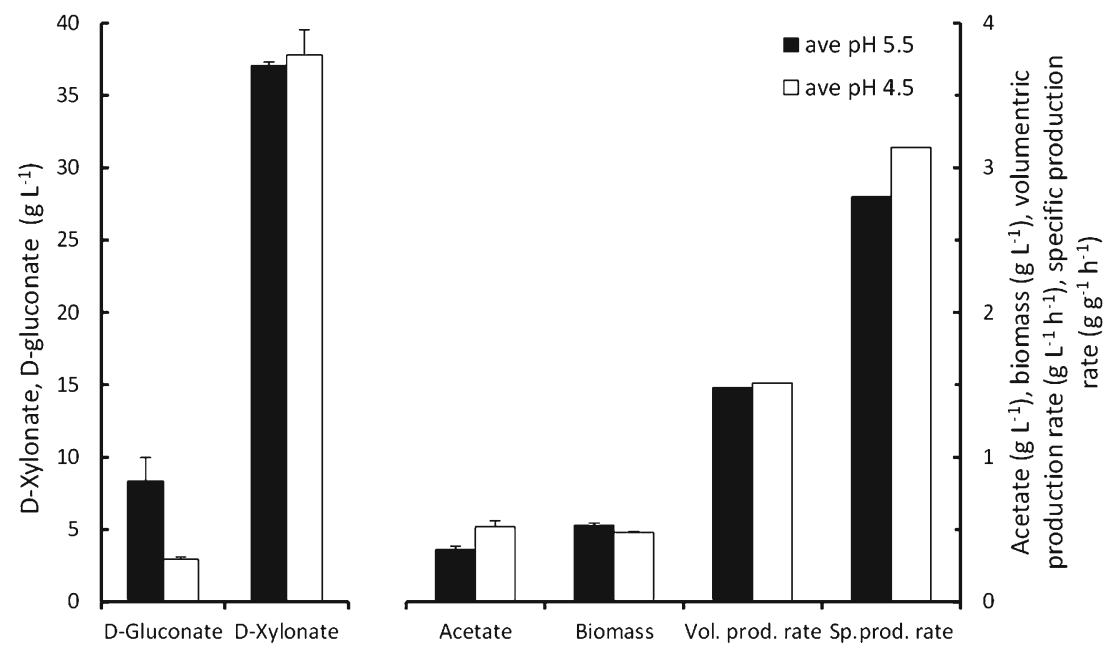
feasibility of producing D-xylonate with yeast, the titres and rates were low compared to those obtained with bacteria (see above) or for other acids produced in $S$. cerevisiae, e.g. lactate $>100 \mathrm{gl}^{-1}$ (Sauer et al. 2010).

Initial attempts at redox engineering to improve $\mathrm{NADP}^{+}$recycling did not improve D-xylonate production (Toivari et al. 2010), and the activity of alternative D-xylose dehydrogenases was assessed in S. cerevisiae (Toivari et al. 2012, Table 1). The C. crescentus $x y l B$ encoded $\mathrm{NAD}^{+}$-dependent D-xylose dehydrogenase was found to have high activity in $S$. cerevisiae, and strains expressing $x y l B$ produced more D-xylonate $\left(17 \pm 2 \mathrm{gl}^{-1}\right)$ at a higher rate than the $\mathrm{X} y d 1$ expressing strain (Table 1, Toivari et al. 2012). In addition to high activity, the xylB had high specificity for D-xylose (Toivari et al. 2012). This increase in Dxylonate production with $x y l B$ compared to $X y d l$ presumably reflects the higher activity of the dehydrogenase in the cytoplasm. However, it may also indicate that production of excess $\mathrm{NADH}$, which can be oxidised in the electron transport chain to generate energy, is preferable to production of excess NADPH. Another $\mathrm{NADP}^{+}$requiring D-xylose dehydrogenase, SUS2DD from pig liver, which was successfully expressed in S. cerevisiae, showed similar activity and production characteristics to the T. reesei Xyd1 (Table 1, Toivari et al. 2012).

Expression of $x y l B$ in the industrial $S$. cerevisiae strain B67002 enabled the production of higher concentrations of D-xylonate (e.g. $43 \mathrm{gl}^{-1}$ ) than with the lab strain, at rates approaching $0.5 \mathrm{gl}^{-1} \mathrm{~h}^{-1}$, i.e. $25-30 \%$ those observed with Gluconobacter and Pseudomonas spp. (Table 1; Toivari et al. 2012).

Only limited research has been carried out on the environmental conditions that are required for good D-xylonate

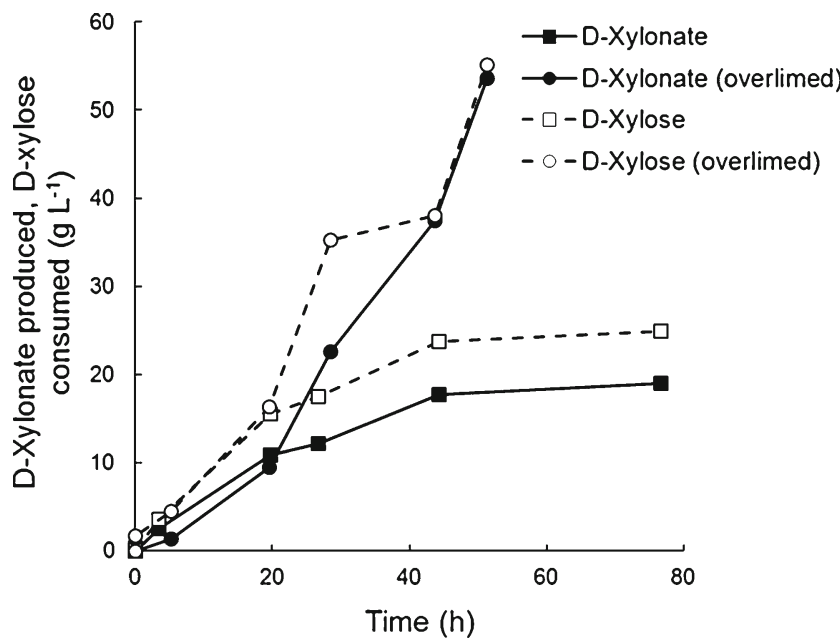

Fig. 5 D-Xylonate produced (solid symbols) and D-xylose consumed (open symbols) by Gluconobacter oxydans ATCC621 in pre-treated wheat straw derived hydrolysate (C5 fraction), with (circles) or without (squares) overliming, and supplemented with $5 \mathrm{~g}$ yeast extract $\mathrm{l}^{-1}$ at $\mathrm{pH}$ 5.6, $30{ }^{\circ} \mathrm{C}$. The hydrolysate contained D-xylose, D-glucose, Larabinose, and acetate. D-Xylonate measurements in untreated wheat straw hydrolysate are shown in Turkia et al. (2010)

production by $S$. cerevisiae. Production has primarily been characterised at $\mathrm{pH}$ 5.5. D-Xylonate could also be produced at $\mathrm{pH} \mathrm{3}$, but production and cell viability were reduced compared to that observed at pH 5.5 (Toivari et al. 2012). Similarly, low productivity at low $\mathrm{pH}$ has also been observed with lactic acid production (Porro et al. 1999). D-Xylonate accumulated intracellularly (Toivari et al. 2012), revealing a potential need to engineer D-xylonate transport. D-Xylonate production has been shown to be

Table 2 Production of D-xylonate from lignocellulosic hydrolysates with G. oxydans ATCC621

\begin{tabular}{|c|c|c|c|c|}
\hline D-Xylose $\left(\mathrm{g} \mathrm{l}^{-1}\right)$ & D-Xylonate $\left(\mathrm{g} \mathrm{l}^{-1}\right)$ & $\begin{array}{l}\text { Volumetric productivity } \\
\left(\mathrm{g} \mathrm{D} \text {-xylonate } \mathrm{l}^{-1} \mathrm{~h}^{-1}\right)\end{array}$ & Hydrolysate & References \\
\hline 25 & $\sim 13$ & 0.2 & Birchwood, steam & Buchert et al. (1988) \\
\hline 25 & $\sim 22$ & 0.3 & Birchwood, steam, ether extracted & Buchert et al. (1988) \\
\hline 100 & $\sim 88$ & 1.2 & Birchwood, steam, ion exclusion & Buchert et al. (1990) \\
\hline$\sim 45$ & $\sim 48$ & $\sim 0.5$ & Birch spent sulphite liquor & Chun et al. (2006) \\
\hline 39 & 17 & 0.4 & $\begin{array}{l}\text { Wheat straw (ABNT), C5 fraction } \\
\text { derived }^{\mathrm{a}} \text { from steam pre-treatment }\end{array}$ & Turkia et al. (2010) \\
\hline na & 54 & 1.1 & $\begin{array}{l}\text { Wheat straw (ABNT), C5 fraction } \\
\text { derived }^{\text {a }} \text { from steam pre-treatment, overlimed }\end{array}$ & VTT \\
\hline 35 & 35 & 0.6 & DDGS (ABNT), acid hydrolysed & VTT \\
\hline 25 & 13 & 0.3 & $\begin{array}{l}\text { DDGS (ABNT), acid hydrolysed, } \\
\text { continuous at } D=0.03 \mathrm{~h}^{-1}\end{array}$ & VTT \\
\hline 23 & 5 & 0.1 & $\begin{array}{l}\text { DDGS (ABNT), acid hydrolysed, } \\
\text { overlimed, continuous at } D=0.02 \mathrm{~h}^{-1}\end{array}$ & VTT \\
\hline
\end{tabular}

When described, cultures were maintained at $\mathrm{pH}$ 5.5-6.5

ABNT Abengoa Bioenergia Nuevas Tecnologias, VTT unpublished data from VTT, M.G. Wiebe personal communication, na not available

${ }^{a}$ Provided by Dr. Robert Bakker, Wageningen University \& Research Centre 
an energy requiring process, with production essentially stopping once metabolisable carbon has been consumed, but resuming when additional co-substrate is added (Toivari et al. 2010). Since most biomass hydrolysates, even C5-enriched fractions, contain some C6 sugars, co-substrate would be at least partly provided from the biomass hydrolysate. Because D-xylonate production produces NADH (or NADPH), which needs to be oxidized, ultimately by channelling electrons to oxygen, the process must be aerobic. However, the energy produced in the reduction of oxygen will provide energy for the process, including D-xylonate transport (if active), $\mathrm{pH}$ homeostasis and cell maintenance.

When a putative D-xylono-lactone lactonase $x y l C$ from $C$. crescentus was expressed together with $x y l B$ in S. cerevisiae, increased lactonase activity was observed by NMR. More extracellular D-xylonate was initially produced than with cells lacking $x y l C$ at both pH 5.5 and 3 (Toivari et al. 2012). The lactonase-expressing strain also sustained higher production at $\mathrm{pH}$ 3. However, expression of the lactonase encoding gene decreased cell vitality and viability when D-xylonate was produced at pH 3.0 (Toivari et al. 2012).

\section{Alternative yeast for D-xylonate production}

D-Xylonate production has also been demonstrated with the D-xylose-utilising yeast $K$. lactis. D-Xylonate was produced in $K$. lactis with the Xyd1 enzyme from T. reesei, which is $\mathrm{NADP}^{+}$-dependent and has relatively low activity. Although the activity levels were similar to those observed in $S$. cerevisiae, $K$. lactis produced more D-xylonate $(6.3 \pm 0.1 \mathrm{~g}$ $1^{-1}$ ) at a higher rate (Nygård et al. 2011), compared to $S$. cerevisiae expressing the same gene. Increasing the substrate concentration led to higher productivity $\left(19 \pm 2 \mathrm{gl}^{-1}\right.$ at rates of $0.16 \pm 0.01 \mathrm{gl}^{-1} \mathrm{~h}^{-1}$, Table 1; Nygård et al. 2011), whereas the equivalent $S$. cerevisiae strains did not increase D-xylonate production when provided higher D-xylose concentrations. The natural ability to utilize D-xylose not only may benefit D-xylonate production by decreasing the need for added co-substrate but also decreases the overall yield and thus should be optimized to support good productivity without substantial loss in yield.

In $K$. lactis the deletion of the xylose reductase (encoded by $X Y L 1$ ) resulted not only in less xylitol production compared to the reductase containing strain but also increased D-xylonate production (Nygård et al. 2011), in contrast to the effect of deleting GRE3 from $S$. cerevisiae, which only reduced xylitol production (Toivari et al. 2010). With K. lactis, oxygen provision affected the conversion of D-xylose to D-xylonate, xylitol or biomass. Metabolism of D-xylose was most efficient with high oxygen provision $\left(12 \mathrm{mmol} \mathrm{O}_{2} \mathrm{l}^{-1} \mathrm{~h}^{-1}\right)$, but even with low oxygen concentration $\left(6 \mathrm{mmol} \mathrm{O}_{2} \mathrm{l}^{-1} \mathrm{~h}^{-1}\right)$, no loss in Dxylonate titre or production rate occurred.
K. lactis is not particularly tolerant to biomass hydrolysates, but its good D-xylonate production ability demonstrates the potential benefit of producing D-xylonate in a D-xylose-utilising non-Saccharomyces yeast.

\section{The prospects for future microbial D-xylonate production}

Although the non-engineered bacteria are very efficient at producing D-xylonate, neither commercial production has been described, nor have cost effective, large-scale separation processes been developed. The current methods, e.g., precipitation or ion exchange, are for small-scale preparations from relatively pure solutions (Liu et al. 2011; Buchert et al. 1986; Devos and Huchette 1981) and would not be adequate for bulk production of D-xylonic acid required for use as a platform chemical, e.g., for polymer or hydrogel production. Since there is no historic market for D-xylonate, there has been no driving force to develop large-scale production. However, with the increasing need to replace petrochemicals and compounds derived from D-glucose, such as D-gluconate, with alternative chemicals, interest in large-scale production and purification of D-xylonate will grow.

Production of D-xylonate by G. oxydans has been limited by complex nutritional requirements and low biomass production, requiring costly inoculum development, even if D-xylonate could then be produced from biomass hydrolysates. Several patents improving biomass production by $G$. oxydans have been published (Zhao et al. 2011; Yuan et al. 2009; Shingoh 2009), but strategies that disrupt the peri- or cytoplasmic glucose dehydrogenases (Shingoh 2009) are expected to also reduce the D-xylonate production rate. P. fragi would provide more robust inoculum development, but would require more extensive treatment to remove inhibitors from the biomass hydrolysates than G. oxydans (Buchert et al. 1988). G. diazotrophicus may be a reasonable alternative (Attwood et al. 1991), but has not been evaluated in hydrolysate. Another major concern with these bacteria is the range of acidic products produced from the compounds present in lignocellulosic hydrolysates and their separation costs.

Genetically engineered bacteria and yeast now provide new alternatives to the non-engineered bacteria for large-scale production of D-xylonate and are likely to be developed further. The engineered $E$. coli strain provides benefits in having a fast specific growth rate, efficient generation of inoculum, and low nutrient requirements. Yeast such as $S$. cerevisiae and $K$. lactis also have good growth and low nutritional requirements. $S$. cerevisiae and several other yeast (e.g. Kwon et al. 2011) additionally offer good tolerance to the various inhibitors found in lignocellulosic hydrolysates, as well as tolerance to low $\mathrm{pH}$ conditions and even the capacity for acid production at low $\mathrm{pH}$ (cf. lactic acid production at $\mathrm{pH} 3$, Suominen et al. 
2009). The development of genetically engineered production strains opens new doors for the development of robust industrial processes for D-xylonic acid production.

Acknowledgments Work reported in this review has been financially supported by the Academy of Finland through the Centre of Excellence in White Biotechnology - Green Chemistry (grant 118573) and the European Commission through the Sixth Framework Programme Integrated Project BioSynergy (038994-SES6) and the Seventh Framework Programme (FP7/2007-2013) under grant agreement no. FP7-241566 BIOCORE. Financial support from the VTT Graduate School is acknowledged (Yvonne Nygård).

Open Access This article is distributed under the terms of the Creative Commons Attribution License which permits any use, distribution, and reproduction in any medium, provided the original author(s) and the source are credited.

\section{References}

Attwood MM, Vandijken JP, Pronk JT (1991) Glucose-metabolism and gluconic acid production by Acetobacter diazotrophicus. J Ferment Bioeng 72:101-105

Berghäll S, Hilditch S, Penttilä M, Richard P (2007) Identification in the mould Hypocrea jecorina of a gene encoding an NADP $\left(^{+}\right)$: D-xylose dehydrogenase. FEMS Microbiol Lett 277:249253

Brouns SJ, Walther J, Snijders AP, van de Werken HJ, Willemen HL, Worm P, de Vos MG, Andersson A, Lundgren M, Mazon HF, van den Heuvel RH, Nilsson P, Salmon L, de Vos WM, Wright PC, Bernander R, van der Oost J (2006) Identification of the missing links in prokaryotic pentose oxidation pathways: evidence for enzyme recruitment. J Biol Chem 281:27378-27388

Buchert J (1990) Biotechnical oxidation of D-xylose and hemicellulose hydrolyzates by Gluconobacter oxydans. Dissertation, Helsinki University of Technology

Buchert J, Viikari L (1988) The role of xylonolactone in xylonic acid production by Pseudomonas fragi. Appl Microbiol Biotechnol 27:333-336

Buchert J, Viikari L, Linko M, Markkanen P (1986) Production of xylonic acid by Pseudomonas fragi. Biotechnol Lett 8:541-546

Buchert J, Niemelä K, Puls J, Poutanen K (1990) Improvement in the fermentability of steamed hemicellulose hydrolysate by ion exclusion. Process Biochemistry 25:176-180

Buchert J, Puls J, Poutanen K (1988) Comparison of Pseudomonas fragi and Gluconobacter oxydans for production of xylonic acid from hemicellulose hydrolyzates. Appl Microbiol Biotechnol 28:367-372

Buse R, Onken U, Qazi GN, Sharma N, Parshad R, Verma V (1992a) Influence of dilution rate and dissolved-oxygen concentration on continuous keto acid production by Gluconobacter oxydans subsp. melanogenum. Enzyme Microb Technol 14:1001-1006

Buse R, Qazi GN, Onken U (1992b) Influence of constant and oscillating dissolved-oxygen concentrations on keto acid production by Gluconobacter oxydans subsp. melanogenum. J Biotechnol 26:231-244

Chun BW, Dair B, Porteneuve CB, Jeknavorian AA, Cheung JH, Roberts LR (2003) Beneficiated water reducing compositions. Patent WO0378347

Chun BW, Dair B, Macuch PJ, Wiebe D, Porteneuve C, Jeknavorian A (2006) The development of cement and concrete additive: based on xylonic acid derived via bioconversion of xylose. Appl Biochem Biotechnol 129-132:645-658
Dahms AS (1974) 3-Deoxy-D-pentulosonic acid aldolase and its role in a new pathway of D-xylose degradation. Biochem Biophys Res Commun 60:1433-1439

Devos F, Huchette M (1981) Process for the recovery of alpha-hydroxyand alpha-amino-carboxylic acids from sugar-containing media. Patent US4288619

Galar ML, Boiardi JL (1995) Evidence for a membrane-bound pyrroloquinoline quinone-linked glucose-dehydrogenase in Acetobacter diazotrophicus. Appl Microbiol Biotechnol 43:713-716

Hardy GP, Teixeira de Mattos MJ, Neijssel OM (1993) Energy conservation by pyrroloquinoline quinol-linked xylose oxidation in Pseudomonas putida NCTC 10936 during carbon-limited growth in chemostat culture. FEMS Microbiol Lett 107:107-110

Isbell HS, Hudson CS (1932) The course of the oxidation of the aldose sugars by bromine water. Bur Standards J Res 8:327-338

Ishizaki H, Ihara T, Yoshitake J (1973) D-xylonic acid production by Enterobacter cloacae. Nippon Nogei Kagaku Kaishi 47:755-761

Johnsen U, Schönheit P (2004) Novel xylose dehydrogenase in the halophilic archaeon Haloarcula marismortui. J Bacteriol 186:6198-6207

Johnsen U, Dambeck M, Zaiss H, Fuhrer T, Soppa J, Sauer U, Schönheit P (2009) D-xylose degradation pathway in the halophilic archaeon Haloferax volcanii. J Biol Chem 284:27290-27303

Jokic A, Ristic N, Jaksic MM, Spasojevic M, Krstajic N (1991) Simultaneous electrolytic production of xylitol and xylonic acid from xylose. J Appl Electrochem 21:321-326

Kanauchi M, Bamforth CW (2003) Use of xylose dehydrogenase from Trichoderma viride in an enzymic method for the measurement of pentosan in barley. J Inst Brewing 109:203-207

Kiesling H, Lindberg B, McKay J (1962) Some products of the metabolism of D-xylose by Pullularia pullulans. Acta Chemica Scandinavica 16:1858-1862

Kwon YJ, Ma AZ, Li Q, Wang F, Zhuang GQ, Liu CZ (2011) Effect of lignocellulosic inhibitory compounds on growth and ethanol fermentation of newly-isolated thermotolerant Issatchenkia orientalis. Bioresour Technol 102:8099-8104

Liu H, Valdehuesa KN, Nisola GM, Ramos KR, Chung WJ (2011) High yield production of D-xylonic acid from D-xylose using engineered Escherichia coli. Bioresour Technol 115:244-248

Lockwood LB, Nelson GEN (1946) The oxidation of pentoses by Pseudomonas. J Bacteriol 52:581-586

Mohagheghi A, Ruth M, Schell DJ (2006) Conditioning hemicellulose hydrolysates for fermentation: effects of overliming $\mathrm{pH}$ on sugar and ethanol yields. Process Biochem 41:1806-1811

Niu W, Molefe MN, Frost JW (2003) Microbial synthesis of the energetic material precursor 1,2,4-butanetriol. J Am Chem Soc 125:12998-12999

Nygård Y, Toivari MH, Penttilä M, Ruohonen L, Wiebe MG (2011) Bioconversion of D-xylose to D-xylonate with Kluyveromyces lactis. Metab Eng 13:383-391

Ohsugi M, Tochikura T, Ogata K (1970) The production of D-xylonic acid by Micrococcus sp. Agric Biol Chem 34:357-363

Pezzotti F, Therisod M (2006) Enzymatic synthesis of aldonic acids. Carbohydr Res 341:2290-2292

Pfister K, Sjöström E (1977) The formation of monosaccharides and aldonic and uronic acids during sulphite pulping. Pap Puu 59:711-720

Porro D, Bianchi MM, Brambilla L, Menghini R, Bolzani D, Carrera V, Lievense J, Liu CL, Ranzi BM, Frontali L, Alberghina L (1999) Replacement of a metabolic pathway for large-scale production of lactic acid from engineered yeasts. Appl Environ Microbiol 65:4211-4215

Samuelson O, Simonson R (1962) The formation of aldonic acids during acid sulfite cooking. Svensk Papperstidn 65:685-689

Sauer M, Porro D, Mattanovich D, Branduardi P (2010) 16 years research on lactic acid production with yeast-ready for the market? Biotechnol Genet Eng Rev 27:229-256 
Shingoh M (2009) NADP-dependent glucose dehydrogenase from Gluconobacter oxydans. Patent US 2009/0130705 A1

Stephens C, Christen B, Fuchs T, Sundaram V, Watanabe K, Jenal U (2007) Genetic analysis of a novel pathway for D-xylose metabolism in Caulobacter crescentus. J Bacteriol 189:2181-2185

Suominen P, Aristidou A, Penttilä M, Ilmén M, Ruohonen L, Koivuranta K, Roberg-Perez K (2009) Genetically modified yeast of the species Issatchenkia orientalis and closely relates species, and fermentation processes using same. Patent US 2009/0226989 A1

Suzuki T, Onishi H (1973) Oxidation and reduction of D-xylose by cell-free extract of Pichia quercuum. Appl Microbiol $25: 850-852$

Takagi Y, Sugisawa T, Hoshino T (2009) Continuous 2-keto-L-gulonic acid fermentation from L-sorbose by Ketogulonigenium vulgare DSM 4025. Appl Microbiol Biotechnol 82:1049-1056

Toivari MH, Ruohonen L, Richard P, Penttilä M, Wiebe MG (2010) Saccharomyces cerevisiae engineered to produce D-xylonate. Appl Microbiol Biotechnol 88:751-760
Toivari M, Nygård Y, Kumpula E-P, Vehkomäki M-L, Benčina M, Valkonen M, Maaheimo H, Andberg M, Koivula A, Ruohonen L, Penttilä M, Wiebe MG (2012) Metabolic engineering of Saccharomyces cerevisiae for bioconversion of $\mathrm{D}$-xylose to $\mathrm{D}$-xylonate. Metab Eng 14:427-436

Turkia H, Siren H, Pitkänen JP, Wiebe MG, Penttilä M (2010) Capillary electrophoresis for the monitoring of carboxylic acid production by Gluconobacter oxydans. J Chromatogr A 1217:1537-1542

Weimberg R (1961) Pentose oxidation by Pseudomonas fragi. J Biol Chem 236:629-635

Yuan Y, Yi H, Wang L, Zhou J, Ma Q, Xue J (2009) Method for improving Gluconobacter oxydans to produce 2-keto-L-gulonic acid. Patent CN101603060

Zamora F, Bueno M, Molina I, Iribarren JI, Munoz-Guerra S, Galbis JA (2000) Stereoregular copolyamides derived from D-xylose and L-arabinose. Macromolecules 33:2030-2038

Zhao Z, Wang Q, Xiao Y (2011) Method for increasing Gluconobacter oxydans biomass by fermenting with oxygen-carrier-added culture medium. Patent CN102086445 